\title{
On the Construction of New Countryside in the Pearl River Delta
}

\author{
Deyu Chen
}

\author{
Guangzhou College of Commerce, Guangzhou, China \\ *Corresponding author. Email: chendeyu666@163.com
}

\begin{abstract}
Agriculture, rural areas and farmers have traditionally been the key issues in our country's modernization. Since the reform and opening up, especially the rural areas in the Pearl River Delta region, rely on the superior geographical location and the country's preferential policies to develop rapidly. However, at present, most of them have met the bottleneck of continued development. Based on the pearl river delta region characteristics and existing problems of rural development, put forward the strategic development of the city circle at the established system, makes the integration of urban and rural talent team, accelerate the transformation and upgrading of rural industry, the relationship between urban and rural dual economy and speeding up the reform of rural comprehensive system and so on, to promote socialist new rural construction and development.
\end{abstract}

Keywords: Pearl River Delta region, New countryside, Urban-rural integration, Industrialization, Urbanization.

\section{THE CONNOTATION OF THE NEW SOCIALIST COUNTRYSIDE}

"New socialist countryside" refers to the social state that reflects the rural society in a certain period based on economic development and marked by overall social progress under the socialist system. It mainly includes the following aspects: First, to develop the economy and increase income. This is the primary premise of building a new socialist countryside. It is necessary to increase income by changing old production methods and updating new rural production tools, improving output and efficiency, increasing the variety and quality of crops and expanding the market environment. Second, expand public welfare and promote harmony. We will guarantee children's right to education and raise the level of education in rural areas so that every child can have the opportunity to study. Strengthen the social security system and improve the quality of social security [1-3]. Balance urban and rural development and realize the integration of urban and rural development. Third, the construction of villages and towns, improve the environment. Old houses will be upgraded to improve people's awareness of garbage classification and environmental protection, improve the polluted water environment in rural areas, encourage villagers to plant more trees and protect the ecological environment.
Fourth, cultivate farmers and improve their quality. To strengthen the ideological and moral construction, improve the villagers' ideological and moral level; We should strengthen cultural development in rural areas and enrich farmers' spiritual and cultural life.

Specifically, the so-called "new countryside" includes five aspects, namely new houses, new facilities, new environment, new farmers and new customs. These five are indispensable, constitute the important part of new rural construction together. Both according to the local rural environment to build "resource-saving, environment-friendly" living environment; To improve the local infrastructure construction, improve the living standards of farmers [4-6]; We should improve the ideological and cultural quality of farmers, so that they are equipped with modern quality and become "four farmers" with ideals, education, morality and probability. We should strengthen the construction of rural spiritual civilization and build a better society in rural areas.

\section{THE PROBLEMS OF RURAL CONSTRUCTION IN THE PEARL RIVER DELTA}

First, the lack of resources. In a certain sense, the development of the Pearl River Delta region can be said to be resource-plundering, with serious dependence and 
consumption of resources. For example, almost $80 \%$ of the land in the Pearl River Delta region has been exhausted, and land resources are an important carrier of new rural construction. Another example is the Pearl River Delta, originally rich in water resources, but due to the sharp drop of forest resources in the upstream, the fresh water volume decreases accordingly, and in recent years, the "salty tide" has appeared continuously. What is more terrible is the serious industrial pollution and the rapid deterioration of water quality. Even the mouth of the vast Pearl River is in danger of becoming a Dead Sea. If we do not pay close attention to the inventory, integration and optimization of land resources, strengthen water conservancy construction, strengthen pollution prevention and control, and maintain ecological balance, the problem of land, water and other resources will seriously restrict the construction of the new countryside.

Second, the lag of planning. In the past 30 years of reform and opening up, the pearl River Delta region has made great progress in economic and social development, but many problems have also been exposed, the most obvious of which is the lack of a high-level, high starting point and macro and coordinated planning to coordinate the development of the whole region. Repeated positioning between cities and within cities, vicious competition. Rural planning sees only new houses, no new villages, no new villages, no new communities. There is no effective link between urban and rural planning, lack of coordination in various projects [7], and rural infrastructure construction is particularly weak. The lag of planning has become an important factor affecting the construction of new rural areas in the Pearl River Delta.

Third, the weak quality of the industry. From the present point of view, into the post-industrial pearl River Delta, the industry is still a large weak quality. On the one hand, the primary industry has contracted seriously, with less than $0.46 \mathrm{mu}$ of arable land per capita and agriculture accounting for only 3\% of GDP. Although the secondary industry develops rapidly, accounting for more than half of the total economy, it is mainly labor-intensive and extensive imitation of the "three come and one supplement" economy and "Guangzhou Dialect economy". It lacks independent intellectual property rights and own brands, and its independent innovation ability is weak. The modernization degree of tertiary industry is relatively low, and the gap between it and post-industrial development demand is large. On the other hand, the support of industrial development to rural development is low. Enterprises in the Pearl River Delta have obvious outward processing characteristics, with outward products and outward tax revenue. The industrial development of various industrial towns has a low correlation with the improvement of rural areas, farmers' income and employment. Because of the weak quality of industry and weak support for rural development, the construction of new rural areas in the Pearl River Delta lacks the fundamental focus.

Fourth, ecological deterioration. In recent years, with the rapid economic development, industrialization and urbanization, the rapid increase of floating population, environmental pollution and ecological destruction trend of the Pearl River Delta has also come, and the ecological environment is still in the stage of degradation and deterioration. It can be said that the Pearl River Delta region has been air pollution, soil pollution, water pollution and other comprehensive coverage. The discharge of pollutants from production and living far exceeds the environmental capacity, and the river sections running through the city are generally seriously polluted, and the urban air pollution and noise are quite serious. Environmental pollution and ecological destruction cause huge economic losses, endanger public health and public security, and social conflicts caused by environmental pollution increase year by year, which directly affects social harmony and stability, and has become a major problem to be solved in the construction of new countryside.

Fifth, institutional lag. The reform of rural economic and social system lags behind, and some existing systems are difficult to adapt to the requirements of new rural construction. First, urban and rural areas are still administration-oriented dual structural system, resulting in social division between urban and rural areas. Second, most regions still have a four-level management system of city, county, town and village, which has a long chain of management, high cost and low efficiency. Comprehensive reform has not been carried out, and the management methods are far from adapting to the current situation of economic and social development. Third, most rural areas still implement two-level accounting, and land resources are in the hands of the original production team -- natural villages, which is not conducive to the intensive development of collective economy and unified rural planning and construction. Fourth, the rural social management system is relatively single, it is difficult to form the resultant force of management and development.

\section{THE IDEA OF NEW RURAL CONSTRUCTION IN THE PEARL RIVER DELTA REGION}

In the construction of new socialist rural comprehensive conditions, the Pearl River Delta has occupied a huge advantage in the country. However, it is undeniable that the pearl River Delta is also facing great challenges and obstacles due to the excessive resource consumption and rapid economic development. The Pearl River Delta has been in a higher development platform, what kind of path and model should the new rural construction choose? Generally speaking, the 
construction of new socialist countryside in the Pearl River Delta needs to start from the following aspects:

One is to establish the strategic development system of metropolis circle. The Pearl River Delta region should be viewed with the concept of metropolitan area, which means establishing a spatial organization model of urban-rural integration with big cities as the core, organic integration of large and medium-sized cities, integration of cities and villages. This aspect the key and the most essential one is to break the bondage of administrative region, in the pearl river delta this great blend of urban and rural areas to achieve economic and social division of labor and the organic integration of science, including the layout of the city function orientation, industry development, planning and construction of public facilities, land elements such as resources of overall control and so on. In addition, in view of the present reality, but also very stressed and attaches importance to promote the positive interaction between urban and rural areas, according to the construction of urban and rural overall development philosophy, goals, and advanced the socialization of production and way of life, to better planning and to promote the new rural construction, make the modern urban civilization to the countryside, and compared with traditional organic integration of rural civilization.

Second, we will build an integrated team of urban and rural personnel. At the level of cities and counties (districts), it is necessary to equip modern leaders with long-term vision and strategic thinking for regional construction, ambition and capability in actual combat. At the township level, outside the equipped with economic management talents, must begin to attach importance to know both familiar with economic work, and a good grasp of social management, be good at to do mass work and attention to cultural construction and ecological construction of composite leading cadres, and to establish a perfect service to new countryside construction of modern education, science and technology and cultural talent team. At the village level, we must continue to pay attention to training leaders who can work hard and get rich, especially those who can engage in industrialization, intensification and modernization of agricultural production. In view of the present rural party members' aging, the present situation of the young brain drain, while properly handle a whole treatment, must attach great importance to cultivate knowledge, ability, and promising young people to join the party, to change the structure of rural party member cadres as soon as possible, form a dynamic and charismatic, cohesive subject to new countryside construction.

Third, we will promote the transformation and upgrading of rural industries. Due to the great spatial mobility and external dependence of the "three coming and one supplementing" industry, it is only suitable for the temporary and transitional industry of local economic development. As a result, the pearl river delta in the rural areas in the use of the "three to fill a" industry after completing the process of economic take-off, should take the initiative to explore new ideas and new path of industrial development, make full use of already formed the primitive accumulation of capital, develop the local industry, the independent industry, to speed up the pace of regional industry specialization, actively foster a town thing, takes a county-rural characteristic economy, Lay a solid economic foundation for new rural construction. In the meantime, take effective measure even, quicken agricultural industrialization, modernization process. The secondary and tertiary industries in cities should consider how to strengthen the correlation with the construction of new countryside while transforming and upgrading, so as to provide strong industrial support for the construction of new countryside.

Fourth, we will straighten out the dual economic relationship between urban and rural areas. In the past 30 years of reform and opening up, the majority of rural areas have sacrificed a lot of interests for the development of cities, and it is indeed time to adjust the economic relations between urban and rural areas and cities to "feed" and "repay" rural areas. To establish and perfect the public finance system as soon as possible, provincial, city and county (district) at all levels, in respect of taxation, finance into must be inclined to the rural, such as education, health, science, culture of county-rural career development and public facilities, sewage treatment, ecological maintenance, river regulation, etc., provincial, city and county (district) in addition to also a lot of history to the rural debt, There is a more through institutional reform to solve the problem of long-term rural development. In order to straighten out the dual economic relationship between urban and rural areas more quickly and better, a fundamental reform measure is that the Pearl River Delta region can implement the administrative system of provincial administration and county administration as soon as possible.

Fifth, we will accelerate the reform of the comprehensive rural system. We will further deepen all rural reforms, make innovations in systems and mechanisms, and address institutional obstacles and structural problems that hinder rural development. At present, we should focus on strengthening the building of party organizations and grassroots political power in rural areas, improving the mechanism of villagers' self-governance, accelerating the reform of the rural joint-stock cooperative system and the rural management system, and establishing and improving the rural social security system as soon as possible to provide guarantee for promoting the construction of a new countryside. To be specific, in the Pearl River Delta region, starting from the city level, to counties (districts), 
towns and villages, it is completely possible to implement the integration of the party and government leadership "shoulder to shoulder"; Most of the countryside, can implement administrative village land level concentration, economic level accounting; In rural areas where conditions are ripe, we should speed up the process of transforming the country into a shareholding system and transforming villages into residents.

\section{CONCLUSIONS}

Industrialization and urbanization in the Pearl River Delta region have been on a higher development platform, and the problems to be resolved in the new rural construction are obviously different from those in the central and western regions of China. The path and mode of contemporary rural construction should not be separated from its existing social and economic development and resource environment background, and should be driven by promoting industrialization, urbanization and agricultural industrialization. Therefore, on the one hand, we must re-examine the problems of current industrialization and urbanization, integrate the construction of new countryside into them, drive urbanization with industrialization, and fight against agriculture with industry. On the other hand, vigorously develop the rural economy, giving full play to the advantages of local industries in rural areas, and promote rural industrialization, agricultural industrialization and urbanization. Only by combining inside and outside, can we effectively promote the construction of new countryside, achieve the win-win interaction between urban and rural areas, achieve the integration of urban and rural areas, and then comprehensively promote the modernization of the whole region's economy and society.

\section{REFERENCES}

[1] Ge Fuqiao. Experience, problems and Enlightenment of New Rural Construction -- Reflections on the survey of 100 Villages of Socialist New Rural Construction in Guangdong Province [J]. Chinese Rural Economy, 2021(S1):35-39.

[2] Wang Hao, Xie Yuexin. The present situation and countermeasures of agricultural and rural economic structure adjustment in Guangdong Province [J]. Science and Technology Progress and Countermeasures, 201, 25(5):104-107.

[3] Guo Li, Zhang Jia 'en, LIU Xingchun. Modern Agricultural Science and Technology, 2020(13):197-198.]

[4] MA J H. Seven constraints on the construction of new rural areas in the Pearl River Delta during the 11th Five-Year Plan. Modern Township, 2006(7):24-29.
[5] LIANG Y F. Study on countermeasures to improve the development level of basic education in rural areas of pearl River Delta. Essays on Modern Education, 2001(2):33-38.

[6] Yang J. Thinking on some problems of guangdong agriculture and rural economic development in the new stage. Southern Rural Areas, 2004(4):25-28.

[7] Zhang Deyang, PENG Li, Wu Xia. Reflections on promoting the construction of new countryside in Guangdong province $[\mathrm{J}]$. Southern Countryside, 2006(1):12-15. 